\title{
Correction to: A multi-group higher-order factor analysis for studying the gender-effect in Teacher Job Satisfaction
}

\section{Carlo Cavicchia $^{1}$ (D) . Pasquale Sarnacchiaro ${ }^{2}$ (D)}

Published online: 21 April 2021

(c) Sapienza Università di Roma 2021

\section{Correction to: METRON (2021)}

\section{https://doi.org/10.1007/s40300-021-00204-x}

The original article presented a printing error. Equation (6) should be corrected as follows:

$$
P\left(c_{s}^{M}>c_{s}^{F} \mid c^{M} \leq c^{F}\right)=1-\sum_{\forall i, j} \frac{I\left(2 \bar{c}_{s}^{M}-c_{s j}^{M}-2 \bar{c}_{s}^{F}+c_{s i}^{F}\right)}{N^{2}}
$$

The online version of the original article has been updated, and it can be found at https:// doi.org/10.1007/s40300-021-00204-x.

Publisher's Note Springer Nature remains neutral with regard to jurisdictional claims in published maps and institutional affiliations.

The original article can be found online at https://doi.org/10.1007/s40300-021-00204-x.

Carlo Cavicchia

cavicchia@ese.eur.nl

Pasquale Sarnacchiaro

sarnacch@unina.it

1 Econometric Institute, Erasmus University Rotterdam, Rotterdam, The Netherlands

2 Department of Economics Management and Institution, University of Naples Federico II, Naples, Italy 